\title{
The Study of Human Behavior in Fire Safety Engineering using Experiential Learning
}

\author{
John Gales, Lauren Folk, and Claudia Gaudreault \\ Carleton University \\ Corresponding Author: john.gales@ carleton.ca
}

\begin{abstract}
Carleton University has re-launched one of its flag-ship courses in the field of Fire Safety Engineering: People in Fires. Detailed and concrete experiential learning activities created for this course are discussed. The activities are evaluated on their ability for the students to meet complicated learning objectives involving human behavior, with the overarching goal being to inform the students of applications for architectural and structural engineering design.
\end{abstract}

Keywords: Experiential Education, Surveys, Human Behavior, Fire Safety Engineering.

\section{INTRODUCTION}

Imagine a revolutionary structure conceived only with three months design, with subsequent approval by authorities having jurisdiction and built in less than a year. Then consider that the building is made of combustible timber with no applied fire protection or even sprinklers. This building is real and to 'code', it strictly uses advanced performance based fire engineering to establish its design.

This structure exists due to consideration of three main reasons: first the design considers the application of advanced structural and fire dynamic knowledge where sacrificial wood charring concepts are applied (char is an incombustible layer of carbon that develops as timber is heated - it protects the inner timber from structural damage); second the design is based on a justifiable understanding of the building's expected occupants and their behavior; and third the design was completed by a team of competent and professional fire safety engineers. This building would not currently be permitted nor supported with confidence in Canada, as these three reasons are not as developed as they are globally.

This timber structure is allowed in that particular global jurisdiction because the education system within that country supports the comprehensive training of a fire safety engineer. That engineer not only has an advanced knowledge of the building's structural behavior during an extreme event like a fire, but also has advanced knowledge of the building's occupants. They understand the occupants' sociological and psychological behavior within their surroundings. These designers and their teams will be able to predict, with reduced uncertainties, how the occupants will behave in an emergency. This designer can thereby competently design the structure to ensure that the occupants can, with reduced uncertainty, get out of a structure (egress and evacuation) safely. In other words, they can quantify the occupants' behavioral performance within the structural and architectural design. These designers can achieve this because the educational system within the jurisdiction in which they practice supports the training of these advanced core concepts (fire dynamics, structural fire engineering, and human behavior in fire).

In Canada from 2001 to 2008, an introductory course existed within the Carleton Fire Safety Engineering (FSE) graduate level curriculum which taught human behavior in fire. This class was called: People in Fires. The course was designed for the research student as an overview of the topic. The course was constructed in light of the introduced alternative solution clause within the National Building Code of Canada. The course began to highlight how conceptual human behavior models, which describe how an occupant uses the space around them in all situations, can aid in the design of buildings. It essentially taught that while it was not possible to predict with full confidence an individual's behavior in a fire, it is possible to identify the underlying theories of human behavior that influence how people's decision making is performed and how they will react and use their space in normal and emergency situations. The practitioner can quantify the process and can apply associated design and architectural features into the structure for this process (see Gwynne and Kuligowski in the SFPE handbook for specific design details of this process [1]). After 2008, the course was discontinued as the practitioner teaching the course tragically passed away. In 2016, Carleton offered the course again (with 21 students registered) and will do so again in 2017 . The reintroduction was due to renewed interest and the associated recruitment of a lecturer and guest lecturers with backgrounds in the subject within the Ottawa area. This graduate level course was taught according to an updated 
curriculum as necessitated by scientific changes which occurred in this engineering discipline since the time it was last offered. Conceptually, the course's goals remain the same as stated above; improve the design of buildings/structures by incorporating the occupants' human behavior.

This study herein is not to compare the new class to the old by discussing the curriculum updates that were required. This work instead studies how a contemporary teaching technique can be utilized to enhance student learning and comprehension in order to cover the breadth of the subject and meet course learning objectives in one calendar semester; namely - by using experiential education exercises to facilitate student experiences, in order to reinforce course theory and improve comprehension. The aim is to improve the discussion process in the class to move to more advanced topics in the limited time available, allowing the students to undertake a significant independent study project on the topic by course end.

Experiential learning activities created for this course and their ability to promote the learning objectives are discussed and evaluated in detail herein. This study explicitly focuses on several class activities (predominately experiential); but notably one called 'The Stair Event'. All activities had the voluntary participation of students. Where applicable, class exercises and evaluations were conducted for quality checks. Activities were supplemented with brainstorming discussions, lectures, and projects to complete the experiential education cycle. Students were able to use their first hand experiences to comprehend concepts taught in the classroom in order to advance through the curriculum. An in-class final evaluation considered the overall impact of advanced learning through the oral presentation of an independent study. Recommendations for engineering curriculum enhancement are proposed and corresponding challenges are discussed.

\section{BACKGROUND}

This section provides background information on the course and on human behavior in a whole. This paper acknowledges that the intended readers will predominately be educators attending the Canadian Engineering Education Association conference with little to no background of the subject area of FSE in general, and human behavior in fire specifically. Indeed, FSE is within its infancy of performance based design application in Canada as compared to other global jurisdictions. Therefore, the authors must provide context of this subject prior to discussing the main activities described in this paper. As such, the course is described and two very brief experiential learning exercises are discussed. Those activities would be the first ones performed by the students in this graduate level class as an introduction to the subject.
The interested reader will find these descriptions essential to understanding the main experiential learning activity performed for this work - hence it is beneficial for the reader to begin with this discussion.

\subsection{People in Fires Graduate Class}

People in Fires, is a graduate level course taught in the winter semester at Carleton University in Ottawa. The course is part of the FSE program at the university within the Civil and Environmental Engineering Department. The evolving curriculum focuses on providing the student with the following core learning modules to reach the aforementioned course objectives:

- What is a fire?

- Environmental (Social) psychology

- Cognition and perception

- Decision making

- Sociology in fire safety engineering

- Movement of people

- Data gathering

- Evacuation modelling and architectural influences

- Building codes (international and domestic)

- Prescriptive versus performance based design

- Managing uncertainty in design

Such a curriculum demands the rapid retention and subsequent comprehension from the student to cover the breadth as there are only eleven 3-hour sessions in which to do so. The course is primarily assessed using assignments, final project, presentation and oral exam. The class is, at the time of writing, one of the few covering this topic globally. Due to the degree of complexity associated with just one of the topics listed above (which arguably could be a full course of its own) demonstrating to the students the breadth of knowledge in this confined time frame is challenging - especially if they are to competently perform an independent study on the subject. It has to be recognized that by using conventional teaching methods and attitudes in the available teaching time of one course, it would be difficult for the students to thoroughly learn all advanced concepts and be at a design-stage at completion of the course. Therefore, the focus of the class is to provide to the student the experiences, reflections, and discussions needed so that they can examine the course's concepts in greater detail to promote further initiatives in independent study. That is aided with cumulating of an end of year project. To do this, the course is formulated in experiential learning activities where the student voluntarily engages in a safe simulation exercise and experiences a number of the underlying mechanisms associated with each topic first hand through their own actions. The first three of these activities are discussed at length in this paper (the first two briefly discussed to provide context to the reader from outside FSE). Experiential learning in this context is 
becoming essential to contemporary engineering education. This is in part because of some of the aforementioned reasons. The concept is that the student experiences activities in order to learn advanced concepts more quickly, rather than the student engaging in memory activities limited by the duration of the class, and without application. The student reflects upon what they performed typically through discussion followed by lecture. Minor assignments may be involved with the exercises to put concepts into practice.

\subsection{Fire Safety Engineering (FSE)}

Fire is a hazard to our built environment. For about 100 years or so, we have covered this hazard in design through a basis of prescriptive code and guidance rules for both structural performance and in human safety. These design rules can be based on many 'magic numbers' (a FSE term coined by renowned FSE engineer Margaret Law, arguably she is a founder of contemporary performance based fire design) that are at times indefensible in their origins and in some cases are actually not applicable to the design when used outside of the boundaries from which they were defined. In performance based fire designs we must therefore interrogate these values for meaning. Prescriptive design is not inadequate, buildings are not falling down, and human casualties can be considered the lowest in decades - but because we are prescriptive with our guidance we do not know how much or more importantly how little safety is provided - we are protected, but we do not engineer or optimize our safety. The prime motivator for developing fire engineering is designed safety not prescriptive protection. The goal is to understand the specific situation and problem and find the solution which optimizes the occupants' safety - Fire Safety Engineering.

Regardless of which class in FSE is being taught, the beginning lecture in the authors' opinion is to break a convention - have them play with fire (safely). In the primary author's classes the students begin their first lesson (regardless of previous experience) immediately in this learning exercise. This exercise teaches the students the safety theme of engineering (tenability limits), the complexity of heat, and the creation of smoke (associated to safety). Heat and smoke mechanisms in fire are complex chemical actions and reactions; understanding them helps support a basis of performance based fire design. The activity prepares them to consider FSE as a performance based discipline and to treat it as a profession for which education is needed. It teaches the student what 'load' they should design for, rather than which design table they should consult. We put the field in context with this exercise and we start by using a candle, a thermocouple, thermocouple reader, and two matches.

The fire triangle as it is commonly referred to outside of FSE is used to illustrate that a 'fire' only occurs when oxygen, fuel and heat are present (in some quantity). Realistically, a fire is more complex than that description. It is based on precise quantifications of what fuel type, concentrations, and peak magnitudes that occur; however, in essence all are needed at some level. We can demonstrate these mechanisms and their complexity with the candle and a few simple exercises.

To begin, the candle is placed on an incombustible surface so that the students can easily drop the match on the desk with no risk. The students first ignite their candles with a long stem stricken match. The students are asked how hot they think the candle is, as they can normally pass their fingers through the candle without them burning. They therefore believe on intuition that the candle temperature will be below the boiling point of water, 100C. The average quoted temperature was $86+/-10 \mathrm{C}$ in this year's class with 21 responses. The students are led to believe a small temperature based on that exercise, which in this case is perfect to begin with. The peak temperatures (rather heat) that fire can radiate is important; the human body can sustain only so much heat before being incapacitated (a tenability limit), and the structure can withstand only so much damage from extreme temperatures before it fails [2]. We can take this information (human tenability and structural performance) in a quantified engineering basis, to calculate the Available Safe Evacuation Time (ASET) an occupant has in a building to move away from a region of risk to one of safety. Using a thermocouple attached to its reader, the students then measure the temperatures in and around the candle as an approximation of heat. They immediately see that the peak temperature within the flame is in excess of 900C, whereas regions surrounding the candle's flames approach 150 to $400 \mathrm{C}$ but are highly variable. All temperatures were thus well above the student's guesses even those outside of the fire (see Fig. 1). The students now know that the fire is of extreme temperature and that the temperature around a flame is not uniform, an incorrect assumption that is the basis of our prescriptive fire guidance. Regarding why a hand does not burn when it passes through the candle's flame, it teaches the students that we retain moisture in our bodies which resists heat. When the moisture evaporates, which is easily done in a fire without even being in the flame, we will burn ourselves (an experiential learning activity gladly not performed); a tenability limit we design against. The activity continues where the student uses a second match and lights it from the candle, takes it away, and extinguishes the candle flame. A trail of smoke remains, extending up from the wick of the candle. The student is directed to place the lit match into the trail of smoke. Ideally, the smoke ignites and the flame travels to the wick of the candle. The candles is lit again. The learning objective is to teach the students what smoke is, having adequately demonstrated what heat is before with the thermocouple. Smoke is actually the gaseous wax which emerges from the candles' hot wick 
after heating. This is a process which the students can easily see as the wax starts as a solid and melts to a liquid after heat is applied. The wick of the candle, like a straw, draws up this molten wax; the combustible wick heats the molten wax further causing it to be become a gas. The gas mixes with oxygen and with a sustained heat source it gives off light in a chemical reaction that we call fire. The reactions occur and the wax breaks down (to extinction). However, if the fuel does not break down enough as it heats, it emerges as smoke above the visible flame. The process continues until the fuel is gone, or oxygen flow to the candle is interrupted. If the right amount of smoke mixes with the right amount of air, the smoke can ignite again if a heat source is re-introduced. This is the concept of flammability, and relates to tenability in a room. Tenability limits are used to describe the thresholds that people can experience before incapacitation and/or death. If the materials in a room are subjected to a fire and they create significant amounts of smoke, with the right amount of added oxygen, say by an occupant opening a window or door, flashover can occur, where everything within the room may simultaneously ignite, radiating extreme and fatal heat. The candle in this exercise is very small and so the gaseous wax in this emission is not life threatening to the extent of producing a flashover - these important FSE concepts can be safely described in this experiential exercise. A candle can cause a massive fire though, and it is lectured to the students the life losses associated with candle fires based on current statistics - they are high.

As the students now know smoke can be lethal in itself and due to its constituents. They now understand tenability limits and we can begin teaching the human behavior component of the course; how to keep occupants safe and ensure that these limits are not exceeded, and how to get occupants out of the building before the risk of exceedance occurs.

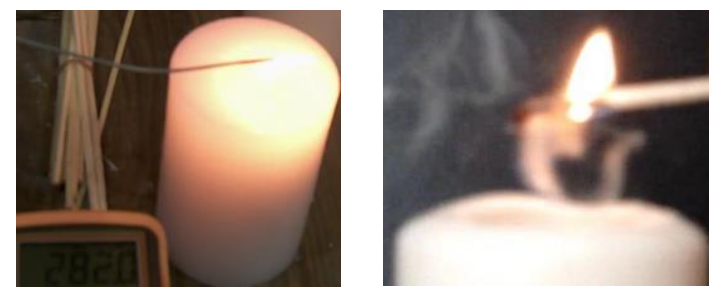

Fig. 1. Candle demonstrates tenability limits: Left heat; Right - ignition of a candle's smoke trail.

To build on this, a second experiment done in an isolated controlled setting can be relayed to the students to show how different types of materials generate different levels of smoke; some very toxic. The goal would be to put into practice the lesson of tenability and safety, and emphasize that smoke can kill (see Fig. 2). While the candle is lit, there is only a small amount of smoke because complete combustion (the breakdown of gaseous wax) is nearly occurring. In more complicated building materials like polymers, the material undergoes incomplete combustion - it does not completely burn off and consequentially produces smoke. This smoke can extend beyond the visible flame, as seen in Fig. 2. The material shown is not 'Victorian' like a candle but is of 'contemporary' nature and would contain high levels of Hydrogen Cyanide (HCN). This is performed safely by demonstration in a video to the students; they cannot perform this experiment due to health and safety risks

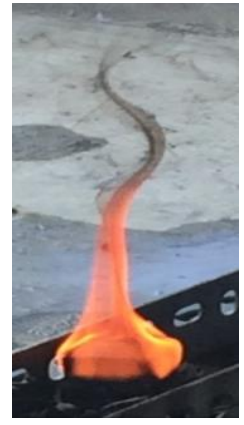

Fig. 2. Other fuel types (styrene based polymer) and smoke emissions which show the concept of

incomplete combustion (shown to students by video safely); similar to room fires in real buildings.

\subsection{Environmental Social Psychology in Engineering}

There are numerous practitioners highlighting how engineering education needs to include psychology even outside FSE. This relevancy is justified based upon how design deals with the interaction of individuals and their settings (environmental social psychology). In FSE, these concepts extend to how an occupant will problem solve and make decisions. Eventually this determines when and how they will act, and how they will behave in a certain space, concepts that all intertwine (based on informational social influence, perception and cognition). In psychology, our spatial orientation and our ability to find our way in an emergency is directly related to way finding - how we problem solve and the approach and route that we use.

The course's second lesson was to conduct an experiential learning exercise which focused on environmental social psychology. This exercise extended over the first and second class of the course, with the students participating in the activity on the first day, and reflecting on and conceptualizing the data in discussion and lecture on the second day.

On the first day of the course, this exercise had the 21 students, led by the instructor, utilize the underground tunnel system at Carleton University to arrive at the candle exercise (lab location) as described in Section 2.2. After the exercise, the students were once again led through the tunnel system following the same route in reverse (Fig. 3).

When the students arrived in class they were given a paper based exercise and told to reproduce the path taken within the tunnel system by memory (see Fig. 3 for the 
correct response) and to comment on any observations made in the tunnel system. The observations would be put into application through related case studies in lecture.

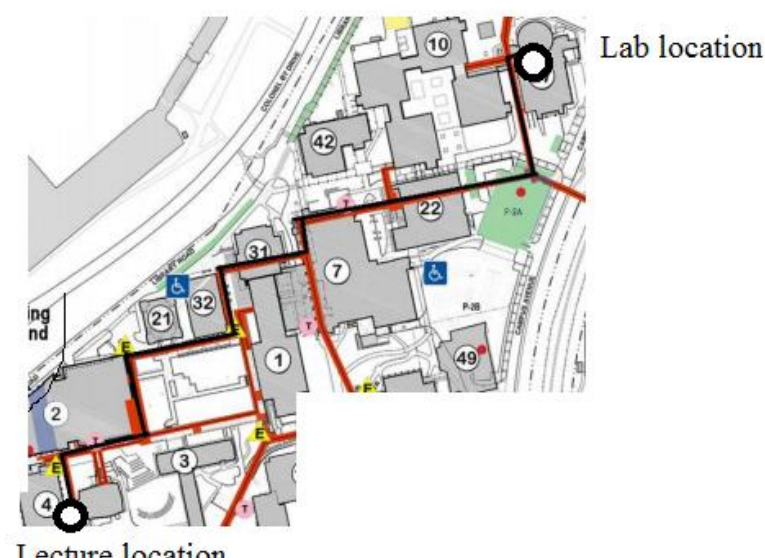

Lecture location

Fig. 3. Carleton University Tunnel system as used for the cognitive psychology exercise

The students commented on observed aspects of environmental social psychology: Appropriation; an affiliation to an item or person, where occupants may take and carry personal belongings with them while traveling, as we tend to recognize personal belongings as extensions of ourselves. Comments were made on how students carried their belongings between locations. Crowding; as the students moved through the tunnels they encountered various psychological crowds from passing groups, travelling in like cultures and personalities, dependent on informational social influence, at times blocking the path of the hall. In an emergency these crowds can contribute to congestion. Personal privacy; the configuration and spacing within the crowd, allowing for people to travel closely beside or behind one another while accounting for personal comfort (naturally walking directly beside another individual they did not know would not likely occur) and the sway as they walk - body sway. The students would have a certain degree of room around them as they walk, including a space away from the wall, which would dictate how much room they would occupy in the tunnel.

The more fundamental concept that the students were to observe and reflect upon in this exercise was how they collectively progressed and moved through the tunnel system in groups. The practice of timing individuals' movements is applied in FSE with the hydraulic (fluid) model. The tunnel system could be perceived as a series of interlocking pipes where people 'flow like water' (Fig. 4). This type of behavioral model is common place, but with considerations of environmental social psychology as well as various social influences on behavior, the model has limitations. The students' experiences in this exercise can highlight these limitations, and participation in the lecture quickly assisted in putting these limitations into context. The students were able to see first-hand through their own and others actions some basic conceptions of the hydraulic model to spur further thought on the subject.

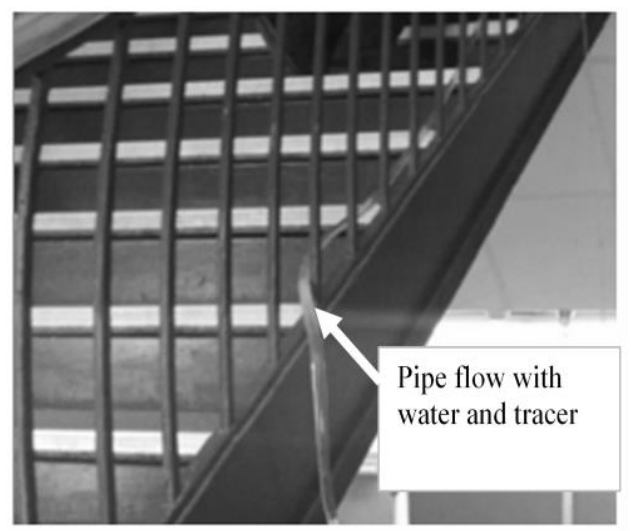

Fig. 4. Education with fluid tracers to measure flow rate as people flow, can be misleading.

As mentioned, the other component of the assignment was reproducing the route taken. The results of each student's assignment were made anonymous after submission by removing identifiable information. They were shown and discussed during the next lecture. The experiential exercise saw a variety of answers which were used in class to illustrate cognitive psychology aspects of decision making which is essential to how an individual would cognitively define and locate a familiar and unfamiliar route in the event of an emergency. The majority of the student-drawn maps were reproduced with reference to specific sensory aspects (smell, touch, kinesthesis, and hearing). Sensory terminology can be used to help the mind associate information to working memory and eventually, if used frequently, to long term memory. Of the student participants, 38\% identified that they had never used the tunnels before (mostly visiting students from the University of Ottawa) and $62 \%$ identified that they had frequently. Of this $62 \%$ who used the tunnel frequently, almost no students indicated sensory based land marks; whereas in the $38 \%$; most students indicated sensory based land marks (i.e., the smells of a coffee shop, steep slopes etc.). It was concluded that those who were familiar with the tunnel system did not rely on immediate sensory indicators for way-finding. This directly allowed the instructor to introduce these cognitive aspects to the student in class, and discuss how sensory experiences feed to our working memory; and how the long-term memory would work.

The exercise, of the tunnels, introduced the students to the concepts of way finding. The next experiential learning exercise would further explore this topic, bringing it together with the concept of human movement. This exercise, was titled 'The Stair Event'. The activities therefore begin to build on each other in a cycle which is the learning method of the common model for experiential education [3]. 


\section{THE STAIR EVENT}

Prior to the Stair Event, the previous experiential activities were expanded upon with a supplementary inclass and take home assignment to introduce the students to the concept of Required Safe Evacuation Time (RSET) the time required for an individual to travel from their location at the time of incident to a safe location. This time represents a formulation of two basic components which subdivide as pre-movement time and movement time. Premovement involves the time of detection, warning, and ceasing of an occupant's current activity; whereas movement time is the occupant's travel time from hazard to safety. RSET is calculated and compared to ASET where a margin of safety is defined. For the in-class assignment prior to 'the Stair Event' the students were asked to predict their pre-movement time, and movement times during class. After completion of their estimation, they were then told to actually 'time themselves' that evening in a take home assignment. The learning intention here was to illustrate to the student the concept of how much time they individually would take to move to safety, and the variability associated with individuals of the same occupancy type (Fig.5).

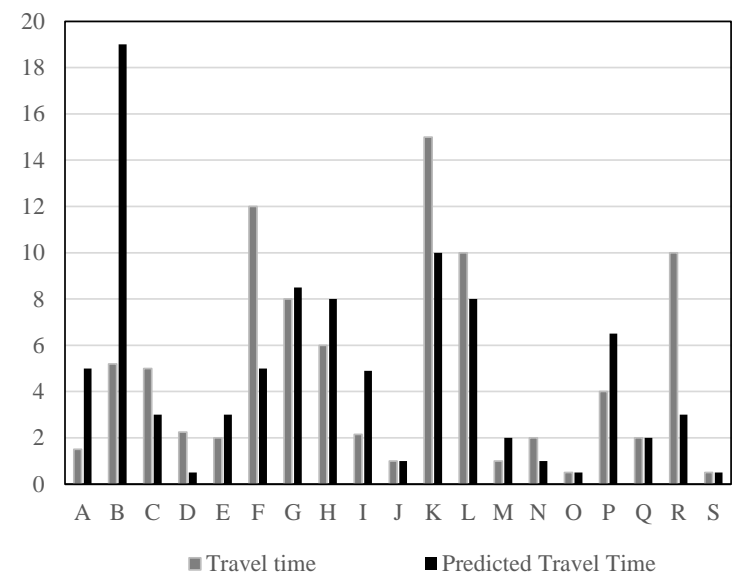

Fig. 5. Predicted and actual travel times for student residential occupancy

The take home assignment assumed that the student egressed solitarily, whereas in a real emergency scenario there will be many informational social influences which could direct the movement patterns of individuals and groups. This leads to the introduction of the concept of Emergent Norm Theory (ENT); where individuals work together through milling (define the situation, adopt the appropriate behaviors, and seek a coordinated solution to a shared problem) and keynoting (leadership) processes.

The final experiential learning technique, The Stair Event, was performed in the next class by 21 students by conducting a simulated evacuation where they descended the stair well of a high rise tower of over 22 stories at Carleton University. In this exercise the students would descend the tower initially as one group, encountering various realistic obstacles as would be experienced in a real emergency evacuation. The exercise is a contemporary research exercise being performed in various high rise towers throughout the world and generally provides designers with quantifiable movement data for human behavior. After the event, these exercises were taught to the students to illustrate that movement times for design can come from such exercises. The tower was booked for the evening of February $11^{\text {th }} 2016$ when activities would be minimal within the building. Fig. 6, shows a floor plan, while Fig. 7 and depicts the stairwell space.

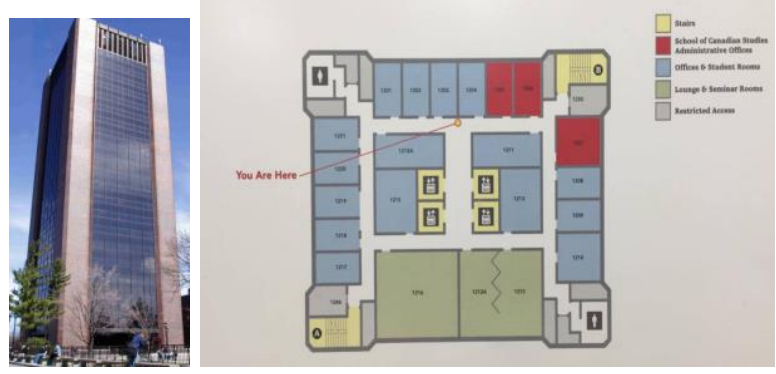

Fig. 6. A university high rise building was used with typical stairwells as defined.

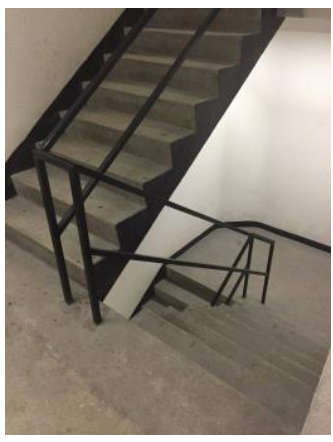

Fig. 7. Stairs only accommodate space for one occupant at a time to descend.

The students were given a 10 minute briefing for safety and risk. They received explicit instructions regarding how to carry out the exercise. In general, their instructions were that they would descend 'Stairwell B' (far right in Fig. 6) in its entirety to the base of the building from Floor 20. Though the students were warned that they should be prepared to listen to any verbal instruction that would modify their route. If the students failed to follow the verbal instructions, exiting through the wrong stairwell, they were considered 'a casualty' in the exercise. When exiting the building they were told to identify themselves by a 'letter' to one of the authors to preserve anonymity, so that they could be timed.

A pre-scout of the building was performed by the authors in order to identify the building's weakest fire 
strategy - and that path would be chosen. The modifications to the route were as follows; at Floor 10 (which had no floor plan posted to assist in identifying the proper evacuation route) the students were verbally told to switch stairwells by an authoritative student (acting as a 'fire-fighter'). They were also told to return to the original stairwell at Floor 7 (which had only one possible route to the stairs - see Fig. 6). A verbal cue is generally more effective than a non-verbal one as it requires perception, attention and comprehension for the occupant. In this exercise the students were blocked from descending at Floor 10 and were thus required to switch stairwells, regardless of the effectiveness of the cue. The fact that there was no clear signage or floor plan on Floor 10 forced the students to use a way-finding exercise in order to identify where Stairwell 'A' was - most students were unfamiliar with the building. This exercise was differed to the students take home assignment, where they were traversing a familiar route. At Floor 7, way-finding would be repeated as one path was blocked by an actual wall partition. Since there was no one blocking Stairwell 'A' at Floor 7 it was anticipated that some students could ignore the instructions from the 'fire fighter'. Counter-flow (people ascending as 'fire fighters' in an emergency) was also simulated. The students were asked upon completion of the exercise to reflect upon and answer the following questions prior to the discussion and lecture:

\section{If you completed the simulation, how long did it take} you to descend?

2. Did you experience any obstructions as you descended? Describe them.

3. When did you feel the first discomfort?

4.If you stopped, at what floor did you stop?

5. What is your age?

The primary learning intent of the questionnaire was to further explore conceptual aspects which effect movement time. Fig. 8 illustrates the groups of students and their movement times as they emerged from the structure.

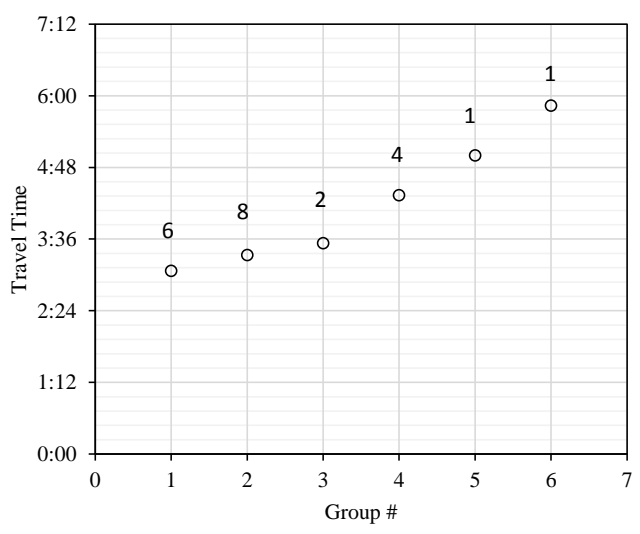

Fig. 8. Student travel time
Four primary groups (more than 2 people) formed in the event. Two lone students trailed at the end. The response of the first group, of approximately $25 \%$ of the participating students, was highly unique. Those students switched stairwells correctly at Floor 10; however, they did not switch back at Floor 7 as previously instructed. During the post exercise discussion, it was identified that at least one of these individuals was motivated to have the 'fastest time'. This student ignored the instructions of the 'firefighter' beyond switching stairwells at Floor 10 (despite the design of this cue to be considered highly effective in conventional literature [1]). It was discussed, that the action of a leader, as possibly seen in the exercise, can influence the behaviour a group. This behaviour conformed to other characteristic traits associated to social norms that individuals perform in real fire scenarios, such as familiarity (to move in a familiar direction - not switching stairs); and affiliation (to move in a social group together as friends).

Beyond behavioural concepts, the experiential learning exercise was meant to illustrate to the students various principals of the movement of people. As previously mentioned, original theories suggest that humans move much like a fluid. In this context, this exercise illustrates that this is a simplified concept. People are complex and can behave very uniquely when moving from one location to another. By limiting the uncertainties associated with human behaviour, we can characterize human movement and design structures accordingly. The surveyed questions were meant to illustrate this, and identified six unique clusters of people emerging from the building at different times. Fig. 8 suggests that people may have travelled in social groupings. Fig. 9 illustrates what obstructions the students encountered.

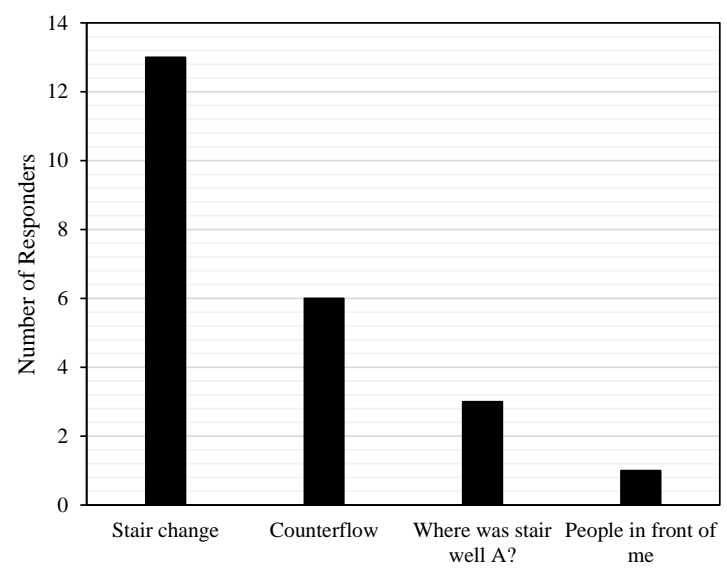

Fig. 9. Obstacles and discomfort

The 'Stair change' was most commonly identified obstruction, where counter flow was identified as second most. Counter-flow was performed with an individual 'actor' ascending the stairs as the students descended. The 'actor' observed, that people stopped descending at the top 
of flight breaks in order to allow this 'actor' to pass. The stairs did not have space to accommodate counter-flow (see Fig. 7). Question 3 assessed that during the descent of the stairs some felt fatigue as they approached the bottom after only 17 floors. This also illustrates that even for fit individuals the use of stairs in an evacuation may be impractical, and the proposal of using elevator systems for egress may have practicality in this regard.

The illustrations of these concepts and the discussion of the event in the class enabled students to see firsthand how these behavioural concepts were indeed real and could even occur in non-emergency scenarios. They also observed first hand an independent timing of their own descent. The key to the experiential learning process for the students was to generate (qualitative and quantitative) data about themselves that they could use to learn concepts taught in class rather than only reading about studies conducted decades ago. As such, the students learn that design as whole, can benefit from inclusion of psychology.

\section{CONCLUSIONS AND OUTLOOK INTO FIRE SAFETY ENGINEERING (FSE) EDUCATION}

The experiential learning exercises discussed in this paper were all performed within the first initial weeks of the class. They were intended to accelerate the students' knowledge of the subject. This enabled more complicated theorems to be covered subsequently, enhancing and expanding the learning outcomes of the class. These exercises were designed to quantify human behavior with the participation of the students.

The complexity of human behavior was identified and readily apparent to the student. It must be recognized that within Canada, these concepts are not commonly utilized within alternative building situations on a design basis. An understanding of these concepts can lead designers and practitioners alike to enable performance based fire engineered designs like those in other jurisdictions.

Overall, the experiential learning activities were met with successes and challenges, as confirmed by in class surveys based on student satisfaction and performance in the students' final case study projects. The students were examined on more advanced theories and applications of contemporary research and design subjects. Components of the experiential exercises were put into further practice. Advanced subjects chosen by the students included: sky bridges, tunnel safety; high rise elevator evacuations; signage; aging populations; roles and leadership. Not all students took on more advanced topics in their study. It is acknowledged by the authors that clarity in learning objectives could be improved as it was the first year this course has been run in eight years.

The future of the People in Fires course remains strong; the course depends on high in-class engagement and participation in order to be successful and carry out meaningful correlations for the students given their own data for comparison against theory. Should the class size decrease, it is unlikely that experiential learning events such as 'The Stair Event' could continue in further years to illustrate group dynamics. Conversely if the class grows too large, the same issue may also occur. Based off this year's results, the authors believe the optimum participation is approximately 30 students.

To help ensure the continuity of the course, a guest lecture series was arranged where notable speakers from Arup Fire, and the National Research Council of Canada. These speakers engaged selected undergraduate students in engineering (about 30) and graduate students from the course (about 21). These students were invited for the three hour late evening lecture on St. Patrick's Day (March $17^{\text {th }}$ 2016).

To achieve a building such as the one described in the introduction of this paper, human behavior cannot be ignored. Fire strategies and design must account for and incorporate this behavior. Human behavior is complex and multi-faceted and requires a reduction in uncertainties. If the designed building can show a validated and verifiable fire strategy that takes into account a level of predictable human behavior, the possibilities for improved performance based fire design in structures and infrastructure is possible. Human behavior and the interactions between humans and their built environment is a critical concept that may be beneficial to incorporate into standard engineering curriculums. It would be a valuable asset for emerging engineers to have a more complete and considerate perspective when conceptualizing the building designs of the future. For this year at least; Carleton has successfully begun initiatives towards these safe goals.

\section{Ethics and Safety Considerations}

Full ethics and safety consideration was employed. The reader should contact the authors prior to performing similar activities for guidance.

\section{Acknowledgements}

N. Hashweh is thanked for data compilation and S. Lefebvre who helped in data collection. NSERC Canada is acknowledged for helping support the research studies of L. Folk and C. Gaudreault during time in which this publication was performed.

\section{References}

[1] Hurley, M. SFPE Handbook of Fire Protection Engineering. Springer 2015. 3000pp.

[2] Gales, J. et al., Structural Fire Testing, Where are We, How did we get here, where are we going? ICEM 15,2012, 25 pp.

[3] Kolb, D.A. Experiential learning. Englewood Cliffs, NJ: Prentice Hall. 1984. 